at at least one of the meetings of the British Medical Association, where his contributions to the discussion are characterised by their brightness and point. All who met him will recognise the aptnes: of the application of these two qualities to Professor Schrötter in all his relations. Although the sitting of the International Congress was, by the request of the family, not cut short, its proceedings were temporarily suspended, and a number of delegates were deputed to offer their sympathy to Professor von Schrötter's widow and children. Among the more representative of the members of this deputation were Professors Chiari and Fraenkel, and Sir Felix Semon. Those of our readers who have had the good fortune to know the deceased professor personally will join most cordially in their expressions of sympathy and regret.

\title{
SUBMUCOUS RESECTION OF THE NASAL SEPTUM IN CHILDREN.
}

At the last meeting of the Laryngological Section of the Royal Society of Medicine ${ }^{1}$ a case of adenoids and slight deflection of the septum was brought forward for the purpose of eliciting opinions as to what operation, if any, was indicated. The discussion diverged somewhat from the original question, and, by the judicious courtesy of the President, was allowed to wander, as the Section obviously desired, in the direction of the consideration of the justifiability of "submucous resection" of the septum in children. In general the opinions coincided with those expressed by several speakers in the Section of Laryngology and Otology at the Toronto meeting of the British Medical Association. ${ }^{2}$ Dr. McDonagh ${ }^{3}$ there expressed himself as follows: "Finally, as to the operation in children, I believe that, unless very necessary, it would be well to postpone it until more nearly full development of the nasal framework has taken place. Evidence of Eustachian or middle-ear catarrh, for instance, or other symptoms of gravity, would, I fancy, justify the operation in children, but in such cases surely no more of the cartilage or bone should be removed than absolutely required."

1 Vide abstract report of proceedings in the present number of the JourN. of Laryngol., Rhinol., and Otol., p. 252.

2 Loc. cit., vol. xxi.

3 Loc. cit., p. 619. 
Dr. Otto Freer's opinion was characterised by definiteness and comparative objectivity. ${ }^{1} \mathrm{He}$ said: "Of late purely theoretical objections have been raised against operating upon children before the fifteenth year, the reason given being that the septum takes an important part in the development of the adult nose, one author, seemingly having in mind the removal of the entire septum as the essence of the submucous resection, saying that 'the septum should not be removed during the years of active growth.' Properly done, the submucous resection never removes more than the deflected portion of the septum, and only in extreme cases does this equal one third of the area of the entire septum. 'The important upper anterior part of the cartilage under the triangular cartilages of the external nose is always spared, and there is therefore always a large enough frame left about the window made to maintain the form of the septum in its growth. During five years in which I have resected the deflections of thirty-two children between the ages of seven and fifteen, and of twelve between the ages of seven and eleven, I have seen no damage to the development of the children's noses. The parents would not have been slow to tell of any, and such of the children as I have seen long after the operation have shown, instead of nasal deformity, an improved physiognomy and appearance of health, due to the free nasal breathing established. An undesirable effect of growth noticed in some younger children was a tendency to a partial reproduction of the deflection, but never to any sinking of the nasal bridge. I have also found, although it has lately been asserted that the cartilage is not reproduced, that the septa of such children as I examined in this respect grew firm over the site of the window in the cartilage in a few weeks, and I attributed this to the great regenerative power of children, and to the careful saving of the perichondriam possible with my method of operating, which permits free and minute inspection of the entire operative field. 'The perichondrium is easily left upon and removed with the cartilage if not looked for. Nearly all my deviations in children were extreme, wholly blocked one nostril, and, if sigmoid, both, and injured the patient's health enough to absolutely demand resection. Children should, therefore, not be deprived of the benefits of the operation because of theoretical objections inspired by a timid imagination."

Other speakers fought rather shy of this question; however, important suggestions were made by Drs. Coakley, of New York,

1 Loc. cit., vol. xxi, p. 622. 
and Dr. M. C. Smith, of Lynn, Mass. 'The former ${ }^{1}$ had seen in children with high and narrow palatal arches and septal deformities very beneficial results follow the use of dental splints, which effected a widening of the arch, there being undoubtedly a straightening of the deflected septum and an increased patency of the nasal respiratory passages.

Dr. Smith, ² speaking from the dentist's standpoint, thought if the dentist fulfilled his duty to young patients there would be little need of surgical operation on the septum in later life. $\mathrm{He}$ said: "In children under fifteen years of age with a deviated septum and enlarged inferior turbinates a deformity of the mouth was nearly always found. The arch was narrow and $V$-shaped, the vault high, and the first molars were not more than an inch apart, and might come entirely within the arch of the lower jaw. Such patients should be sent to the dentist and the arch of the upper jaw widened, not by simply tilting the teeth outwards, but by a plate made of vulcanised rubber that would come down over the outer edges of the teeth so as to hold them in their upright position. Pressure should then be applied over the mucous membrane as high as possible above the gingival margin, and the alveolar process forced out bodily, so that most widening trok place in the median line. Now, if the jaw were widened half an inch it would be reasonable to suppose that the anterior part of each nasal cavity would be a quarter of an inch wider, and if the inferior turbinals were drawn an eighth of an inch away from the septum space enough for breathing would be obtained unless a grave condition existed. By means of work done in the mouth it was easy to separate the inferior turbinates an eighth of an inch from the septum and to draw down the septum materially."

Mr. FitzGerald Powell, at the recent meeting of the Laryngological Section, expressed a feeling of hesitation about operations in the nose in children. He preferred to wait until the patient reached the age of sixteen, because one could not be certain what influence submucous resection might exert upon the development of the nose. He asked those Fellows who had had experience of the submucous resection in children what their experience had been.

Dr. Tilley, in reference to this question, stated that deviation of the septum was not met with before the age of seven. Submucous resection was, he said, a difficult operation in childhood on

1 Loc. cit., p. 629.

$=$ Lor. cit., p. 628 . 
account of the scantiness of room. Whether or not the growth of the nose was interfered with by the resection was not yet known. Certainly more regenerative tissue formed in childhood after the operation than in adult life.

Wr. Westmacott had operated on a number of children, his rule being first of all to resect the turbinals and then to await the result; if this proved insufficient he performed Killian's operation, and in all his cases save one the result was excellent. $\mathrm{He}$ had in several cases observed thickening and swelling of the septum after the operation, but this disappeared entirely after a few months. He performed the operation without any fear of thereby interfering with the development of the nose.

Dr. Pegler spoke in favour of the Moure operation, which he had several times performed in children under the age of six, and in one of his cases the result was extremely good, though with the others he was not quite so satisfied.

Mr. Barwell deprecated resection of the turbinals in young children and referred to the difficulty of performing submucous resection in them. In one of his recent cases a return of the obstruction had resulted from post-operative thickening of the septum.

It is obvious that there is still room for uncertainty and difference of opinion in regard to this question, and it is much to be desired that those who have been led to practise submucous resection in children will do their best to re-examine those patients on whom they have operated some years ago, and without fear or favour bring forward their results so as to establish a course of proceeding founded on objective evidence, and not merely on general impressions. At present we should venture the opinion that unless the symptoms are really urgent the operation should be postponed till the development of the nose is pretty well established, but in the opposite state of matters it is quite justifiable to perform it. The indications must, however, be rather more pronounced than in the adult. 